\title{
ПРИЗНАКИ РАЗВИТИЯ РЕГИОНАЛЬНЫХ СОЦИАЛЬНО-ЭКОНОМИЧЕСКИХ СИСТЕМ
}

\author{
(ㄷ) 2021 Фахрутдинова Елена Валерьевна \\ доктор экономических наук, профессор \\ Казанский (Приволжский) федеральный университет, Казань, Россия \\ E-mail: efahr@mail.ru \\ (c) 2021 Грудина Светлана Игоревна \\ кандидат экономических наук, доцент \\ Казанский (Приволжский) федеральный университет, Казань, Россия \\ E-mail:switki@yandex.ru \\ (c) 2021 Иванов Сергей Евгеньевич \\ преподаватель \\ Поволжский государственный университет физической культуры, спорта и туризма, \\ Россия, Казань \\ E-mail: S.Ivanov@tatar.ru
}

Современные условия развития любой социально-экономической системы как в пределах Российской Федерации, так и в мировом масштабе характеризуются как «турбулентные» или нестабильные, о чем свидетельствует большое количество научных публикаций, посвященных исследованию управления в условиях трансформации социально-экономических систем, нестабильности, смене парадигм управления [1]. Конструктивность управления развитием региональной социально-экономической системы требует превентивности реагирования на слабые сигналы, индикаторы изменений во всем объеме регионального пространства. Дополненная авторами классификация признаков развития региональных социально-экономических систем позволит более точно формировать управленческий импульс для усиления сбалансированности и устойчивости регионального развития, что определяет актуальность, теоретико-методологическую и практическую значимость проведенного исследования. Объектом исследования является нематериальный капитал региона как индикатор инфраструктуры, формирующей доверие и социально-экономическую устойчивость в регионе. Предметом исследования выступают социально-экономические отношения по поводу воспроизводства нематериального капитала в региональной социально-экономической системе.

Ключевые слова: нематериальный капитал, регион, социально-экономическая система, инфернальность развития, индекс доверия, устойчивое развитие, нестабильность, управление.

Важнейшим фактором устойчивости системы является нематериальный капитал, выраженный в индексе доверия к существующей системе управления [6]. Поскольку «доверие» есть нематериальный фактор, в строгом смысле, не поддающийся точному изменению, авторы исследования ставят задачу измерения и классификации признаков его формирующих, имеющих как инфернальные (деградационные) последствия, так и трансформационные последствия перехода социально-экономической системы на новый качественный уровень.

Нематериальность ключевого фактора стабильности развития социально-экономической системы провоцирует переход процесса управ- ления социально-экономической системой региона из плоскости в пространство, что также усиливает вероятность создания управляющего события и управления развитием сценария. Следовательно, превентивное управление причиной трансформационного процесса является более эффективным, нежели усилия, направленные на нейтрализацию негативных последствий [2].

Выполним классификацию признаков (причин, создающих трансформационное событие), исходя их теоретически возможных сценариев развития социально-экономической системы. Выявленные сценарии разделим на инфернальные (деградация системы) и трансформационные (переход системы на новое качество 
с полным или частичным сохранением функциональных свойств системы). Предпосылкой к классификации признаков развития системы явилась актуализирующая потребность в диалоге между ключевыми элементами социально-экономической системы, а, следовательно, способность к диалогу, как реагирование на даже слабые сигналы «обратной связи» всех элементов системы [7].

Открытость к диалогу по горизонтальным и вертикальным управленческим направлениям выделяется авторами в качестве ключевого признака доверия, формирующего сценарии устойчивого развития системы. «Глухота» к обратной связи, отсутствие диалога, низкая степень превентивного управления и отсутствие реагирования на трансформационные процессы системы как целое является признаком инфернального развития, приводящего к энтропии социально-экономических систем, формированию сценариев неустойчивого развития. Диалог формирует также сценарии инвестиционного, социально-экономического поведения потребителей, что влияет на экономическую активность жителей региона [3]. Признаки развития региональных социально-экономических систем структурно в представлены в таблице 1. Авторами классифицированы признаки по критерию катализирующего воздействия на совокупность сценариев социально-экономического развития, а так выявлено значение нематериального фактора доверия в адаптации, нивелировании последствий формируемого сценария.

Сочетание управления выявленными четырьмя катализаторами формирует «эффект целого», под которым подразумевается управ- ление системой как целым, в противовес управлению отдельными элементами системы. «Эффект целого» предлагается в качестве нивелирования противоречий, возникающих в процессе перехода от устоявшейся системы управления, основанной на управлении следствиями, к управлению причинами качеств сценариев развития региональных социально-экономических систем.

Качественная определенность целого определяется координирующим это целое признаком-катализатором. Целое предполагает аспект функционирования (социально-экономическая деятельность региона, валовый региональный продукт), аспект связи (диалог), аспект организации (природные, материальные ресурсы региона). Логика научного познания с применением эффекта целого справедливо также учитывает, что целое может по качественным, нематериальным признакам превышать в ценностном выражении сумму частей его составляющих. Этим и интересен данный подход, позволяющий предпринять попытку учета как материальных, так и нематериальных ценностей региона в пространственно-временном и территориальном измерениях.

В логике целого, управление социально-экономической системой региона возможно, в соответствии с результатами проведенного исследования, в четырех вариациях, определяющих дальнейшие сценарии развития социально-экономической системы. Проанализируем каждый вариант подробнее.

Первый вариант развития сценария в аспекте координат размещаем катализатор энтропии региональной социально-экономи-

Таблища 1. Признаки развития региональных социально-экономических систем

\begin{tabular}{|c|c|c|}
\hline Обозначение катализирующего признака & $\begin{array}{c}\text { Усиление сценария развития } \\
\text { системы }\end{array}$ & $\begin{array}{c}\text { Значение нематериального } \\
\text { фактора доверия в нивелирова- } \\
\text { нии сценария }\end{array}$ \\
\hline $\begin{array}{c}\text { Катализатор энтропии региональной } \\
\text { социально-экономической системы }\end{array}$ & $\begin{array}{c}\text { Интернет, социальные сети, до- } \\
\text { ступ к информации деструкции }\end{array}$ & $\begin{array}{c}\text { Анти тренд, сохранение нема- } \\
\text { териального капитала }\end{array}$ \\
\hline $\begin{array}{c}\text { Катализатор трансформационных про- } \\
\text { цессов в региональной социально-эконо- } \\
\text { мической системе }\end{array}$ & $\begin{array}{c}\text { Трансформация как переход } \\
\text { в новое качество }\end{array}$ & $\begin{array}{c}\text { Возможность формировать по- } \\
\text { зитивный сценарий развития }\end{array}$ \\
\hline $\begin{array}{c}\text { Катализатор «диалога внутри элемен- } \\
\text { тов социально-экономической системы } \\
\text { региона }\end{array}$ & $\begin{array}{c}\text { Диалог открывает возможности } \\
\text { для разнообразия сценариев }\end{array}$ & $\begin{array}{c}\text { Обогащение нематериального } \\
\text { капитала региона }\end{array}$ \\
\hline $\begin{array}{c}\text { Катализатор факторов устойчивого раз- } \\
\text { вития региональной социально-экономи- } \\
\text { ческой системы }\end{array}$ & Создание ценностной струк- \\
туры & Устойчивое развитие \\
\hline
\end{tabular}

Источник: составлено авторами по материалам исследования 
ческой системы (таблица 1). Данный вариант сценария предполагает разрушение ценностной структуры социально-экономической системы. Информация создает новую информацию, но в геометрической прогрессии, с искажениями и энтропией существовавших сценариев [5].

Второй вариант предполагает, что «катализатор трансформационных процессов» в региональной социально-экономической системе формирует новую ценностную структуру на базе доверия к происходящим изменениям. Информация в данном целом играет трансформирующую роль, старые сценарии со знаком минус заменяются новыми с позитивными характеристиками.

Третий вариант основан на диалоге между составляющими элементами социально-экономической системы. Катализатор «диалога» внутри элементов социально-экономической системы региона активизирует внутренние ресурсы региона, нематериальный капитал доверия, знаний, социальные ценности, благодаря которым формируется сценарий развития благоприятный и устойчивый к негативным факторам внешней среды.

Четвертый вариант предполагает активизацию ценностей устойчивого развития среди населения региона. Катализатор факторов устойчивого развития региональной социально-экономической системы формирует ценностную структуру на основе сбалансирован- ного развития социальной, экономической и экологической сфер.

Следует отметить, что проанализированные признаки развития социально-экономических систем структурированы в контексте происходящих трансформационных изменений, исследование ориентировано на формирование разнообразия сценариев развития региональных социально-экономических систем с учетом стремительного развития научно-технического прогресса, технологий, цифровой трансформации и «провалом технологий» в области обеспечения сбалансированного уровня нематериального капитала, капитала доверия, который, по мнению авторов, является базисом устойчивого развития социально-экономической системы [4].

Таким образом, проанализировав признаки развития социально-экономических систем, были выявлены четыре варианта организации управления социально-экономической системой региона на основе качественных признаков энтропии и трансформации. Совокупность четырех подходов к управлению предполагает применение эффекта целого к управлению социально-экономической системой, а не к отдельным частям. Значимость исследования заключается в выявлении нового подхода к управлению разнородностью социально-экономической системы через смену координирующего аспекта управления.

\section{Библиографический список}

1. Грудина С.И. Теория развития энтропии региональных социально-экономических систем // «Казанский экономический вестник». 2021. № 3 (53) - С. 24-28.

2. Грудина С.И. (2020) Нелинейные методы исследования нематериального капитала регионов // Грудина С.И., Подгорная А.И. //«Казанский экономический вестник», № 4 (48) 2020., стр. 51-56

3. Колесникова Ю.С., Фахрутдинова Е.В., Юрков Д.В. Привлечение и удержание высококвалифицированных специалистов в Республику Татарстан//Экономические науки, 2020, №12 (193), с. 246-250

4. Колесникова Ю.С. Оценка нематериального капитала стран: методика и сравнительная характеристика//I Российско-Иранский социологический форум. Сборник тезисов докладов участников форума. Москва, 2020. С. 314-324

5. Решетникова И.И. Репутационный капитал как фактор обеспечения конкурентоспособности российского бизнеса: теория, методология исследования проблемы формирования и управления в условиях глобализации рынков. Дисс. доктор. эконом. наук, 2011 г.

6. Столяр В.Ю. Доверие как феномен социально-экономической реальности. Дисс. канд. фил. наук, 2008 г.

7. Grudina S. Methodologikal aspects of investment risk management in the region/S. Grudina, A. Podgornaya // International Journal of Engineering Reseach and Technology ISSN: 0974-3154 Volume 13, Number 12 (2020), pp. $4417-4420$ 